\title{
Cannabis Indoor Growing Conditions, Management Practices, and Post-Harvest Treatment: A Review
}

\author{
Dan Jin ${ }^{1,2 *}$, Shengxi Jin ${ }^{2}$, Jie Chen ${ }^{1,3}$ \\ ${ }^{1}$ Biomedical Engineering Department, University of Alberta, Edmonton, Canada \\ ${ }^{2}$ Labs-Mart Inc., Edmonton, Canada \\ ${ }^{3}$ Electrical and Computer Engineering Department, University of Alberta, Edmonton, Canada \\ Email: *djin@ualberta.ca
}

How to cite this paper: Jin, D., Jin, S.X. and Chen, J. (2019) Cannabis Indoor Growing Conditions, Management Practices, and Post-Harvest Treatment: A Review. American Journal of Plant Sciences, 10, 925-946. https://doi.org/10.4236/ajps.2019.106067

Received: March 14, 2019

Accepted: June 15, 2019

Published: June 18, 2019

Copyright $\odot 2019$ by author(s) and Scientific Research Publishing Inc. This work is licensed under the Creative Commons Attribution International License (CC BY 4.0).

http://creativecommons.org/licenses/by/4.0/

\section{(c) (i) Open Access}

\begin{abstract}
Cannabis has attracted a new wave of research attention as an herbal medicine. To deliver compliant, uniform, and safe cannabis medicine, growers should optimize growing environments on a site-specific basis. Considering that environmental factors are interconnected, changes in a factor prompts adjustment of other factors. This paper reviews existing work that considers indoor growing conditions (light, temperature, $\mathrm{CO}_{2}$ concentration, humidity, growing media, and nutrient supply), management practices (irrigation, fertilization, pruning \& training, and harvest timing), and post-harvest treatment (drying and storage) for cannabis indoor production.
\end{abstract}

\section{Keywords}

Cannabis, Environmental Factors, Growing Conditions, Post-Harvest

Treatment, Indoor Cultivation, Agrology, Agricultural Science

\section{Introduction}

Cannabis is an annual, non-obligate dioecious plant that is used as a complex botanical medicine containing more than 100 identified cannabinoids [1]. Cannabinoids belong to the chemical classification of terpenophenolics, which are widespread in plants. The most important and frequently detected cannabinoids are tetrahydrocannabinolic acid (THCA), $\Delta^{9}$-tetrahydrocannabinol $\left(\Delta^{9}\right.$-THC), $\Delta^{8}$-tetrahydrocannabinol $\left(\Delta^{8}\right.$-THC), cannabidiolic acid (CBDA), cannabidiol (CBD), cannabigerolic acid (CBGA), cannabigerol (CBG), cannabinolic acid (CBNA), cannabinol (CBN), cannabichromenic acid (CBCA), cannabichromene 
(CBC), cannabicyclolic acid (CBLA), and cannabicyclol (CBL) [2]. Cannabis can be classified either as drug-type plants that have high THC concentrations or as fibre-type plants that are referred to as hemp. Biosynthetic pathways for cannabinoids have been research hotspots since their discovery. The most widely-accepted biosynthetic pathway was proposed by Taura [3] [4] and Morimoto [5], in which CBGA is the direct precursor of THCA, CBCA and CBDA, where CBGA is biosynthesised by geranyl diphosphate (GPP) and olivetolic acid [6] [7]. It is crucial to understand how cannabinoids are related with each other when studying cannabis, considering that degradation (including decarboxylation, isomerization, irradiation, and oxidation) can affect the chemical components through improper operations or during long-term storage with unsuitable conditions, which may severely alter experimental results. Biosynthetic pathways for the production of cannabinoids, including degradation products [8], are demonstrated in Figure 1. Current research tends to focus on THC, which is psychoactive. However, non-psychoactive cannabinoids such as CBD, CBG, and CBC also have broad therapeutic potential [2]. Apart from cannabinoids, terpenoids, which are responsible for cannabis's distinctive odour, are receiving increasing attention for their suggested synergistic interactions with cannabinoids [9] [10]. Large amounts of active ingredients endow cannabis with a wide range

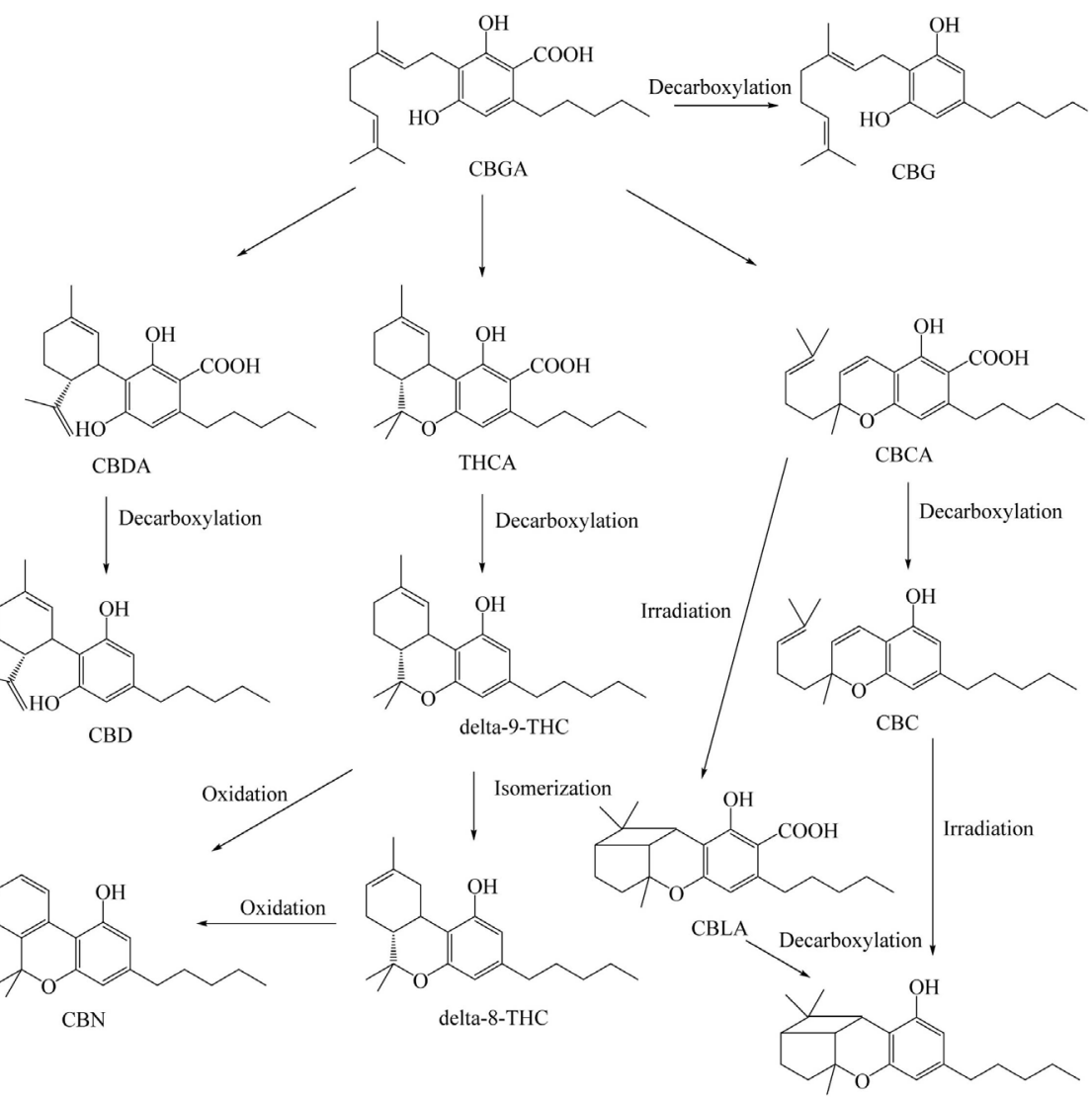

CBL

Figure 1. Relationships between the major cannabinoids found in cannabis [8]. 
of potential therapeutic uses, including the treatment of nausea or vomiting associated with chemotherapy, anorexia associated with AIDS-related weight loss, spasticity and neuropathic pain associated with multiple sclerosis and intractable cancer pain [11].

Since the turn of the $21^{\text {st }}$ century, cannabis for medical purposes has trended globally and became particularly well established in North America. To achieve a consistent profile of effective components in cannabis as an herbal medicine, significant work has been carried out to investigate the mechanism of cannabinoid production. According to recent studies, genetics, growing conditions, manner of drying and storage, and methods of processing and extraction may affect the concentration and profile of pharmaceutically active ingredients derived from cannabis [12]. Within a specific cultivar, the ratio of THC and CBD remains consistent in both male and female plants [13] [14] as well as in leaves and flowers throughout vegetative growth and flowering stages [15] [16] [17]. However, the density of floral bracts and bracteoles that carry glandular trichomes, where cannabinoids and terpenes are biosynthesized and stored, is higher in female plants than in males [2]. Concentration also varies in different plant parts, decreasing in the order of inflorescences, leaves, stem, seeds, and roots [13] [18]. The ratio of THC to CBD is a qualitative trait and the total yield of THC plus CBD is a quantitative trait [19]. Based on this concept, another study calculated cannabinoid yield in a fixed cultivation area as the product of four components: 1) total dry, above-ground biomass; 2) inflorescence leaves and bracts as a proportion of total plant biomass; 3 ) total cannabinoids in the inflorescence leaves and bract fraction; and 4) "purity", the proportion of one cannabinoid out of total cannabinoids [14]. The last component "purity" is a qualitative trait controlled by a simple genetic mechanism that is minimally affected by environmental factors, while the first three components are quantitative traits controlled by different polygenic mechanisms that are heavily affected by the environment [14].

$$
\begin{aligned}
& \text { Cannabinoid yield in a fixed area } \\
& =\frac{\text { One cannabinoid }}{\text { Total cannabinoid }} \times \frac{\text { Total cannabinoid }}{\text { Yield of inflorescence }} \\
& \quad \times \frac{\text { Yield of inflorescence }}{\text { Yield oftotal plant biomass }} \\
& \quad \times \text { Yield of total plant biomassin a fixed area }
\end{aligned}
$$

In the modern cannabis industry, strains with high THC potency are predominantly propagated in controlled environment systems, such as growth chambers or greenhouses [20]. The process starts with seeds or cuttings and uses light schedules to trigger and control the duration of the vegetative and flowering stages [12] (Figure 2). Environmental factors, including growing conditions, horticultural management practices, and post-harvest processing (curing, extraction, etc.), combine with genetics to contribute to the variation in medicinal profiles of the final products. The Dutch government has issued a quality 


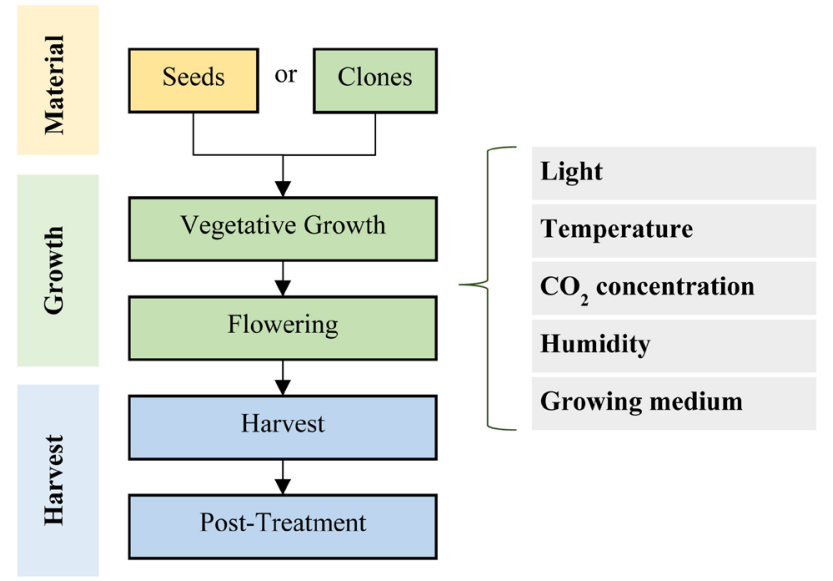

Figure 2. Environmental factors throughout the growing process impact cannabis yield and quality.

assurance system for standardizing cultivation, harvesting and processing of cannabis, including strain, growing medium, light cycle, light intensity, colour temperature of the lighting, humidity, temperature, ventilation, plant age at harvest, time of day for harvesting, drying facility humidity and temperature, drying facility ventilation rates, and drying time [21]. The American Herbal Pharmacopoeia (AHP) has also issued standards of identification, analysis, and quality control of cannabis based on peer-reviewed literature [2]. This article provides a comprehensive review of the current scientific knowledge on horticultural practices for indoor medical cannabis production. Harvest yield and consistency depends on environmental factors, which have interdependencies and interactions. Changes in one factor may have profound effects on how the plants respond to others [22]. Therefore, an integrated approach to analyzing growing practices is required.

\subsection{Growing Conditions}

\section{Light}

Light, both the quality (spectrum) and quantity (intensity), plays an important role in cannabis cultivation in controlled environmental systems, where plants capture energy from light and assimilate $\mathrm{CO}_{2}$ and water into dry matter through photosynthesis.

Light spectrum. Plants utilize light in the visible spectrum between $400 \mathrm{~nm}$ and $700 \mathrm{~nm}$, which is typically referred to as photosynthetically active radiation (PAR). Blue light tends to decreases internode length while a low red/far-red ratio promotes stalk elongation [23]. Ultraviolet A light (UVA, $315-400 \mathrm{~nm}$ ) helps reverse damage to DNA caused by Ultraviolet B light (UVB, $280-315 \mathrm{~nm}$ ) [24] [25]. UVB is reported to increase THC levels in plants; THC is thought to be a UVB photo-protectant [26] [27] [28]. Lydon (1987) found a significant linear relationship between THC content (mg/g d.w.) in floral tissue and UVB dose in drug-type plants, whereas other characteristics such as physiology, leaf mor- 
phology, and content of other cannabinoids (such as CBD) in drug- and fibre-type plants were unaffected [28]. THC content in floral tissue increased from $25 \%$ to $32 \%$ when the daily effective UVB dose was raised from $0 \mathrm{~kJ} / \mathrm{m}^{2}$ to 13.4 $\mathrm{kJ} / \mathrm{m}^{2}$. However, this paper only reviews two chemotypes (one each of drug- and fiber-types) and three levels of daily effective UVB doses $\left(0,6.7\right.$, and $13.4 \mathrm{~kJ} \cdot \mathrm{m}^{-2}$ UVB), thus more data are required to draw firm conclusions.

For indoor cultivation, commonly used lamps include fluorescent lamps (FL), metal halide lamps (MH), and high-pressure sodium lamps (HPS). The ability to transform electrical energy to PAR varies between lamps, as does the spectra emitted. For example, the type of phosphor used to coat the surface of CFLs determines the spectral output. Whereas $\mathrm{MH}$ lamps emit insufficient red light to produce heavy flowers, HPS lamps are heavily concentrated in the yellow, orange, and red spectra with a small amount of blue. A combination of several lamps may be utilized to cover desired wavelengths.

More recently, light emitting diode (LED) fixtures with adjustable spectra have been developed. One study compared the effects of three light spectra, including one HPS and two types of LEDs (AP673L and NS1), on the morphology and cannabinoid content of cannabis clones [23]. The spectrum produced by HPS was 96\% PAR and was heavily concentrated with green/yellow (68\%) and orange/red $(21 \%)$ and less concentrated in violet/blue $(8 \%)$. In comparison, the AP673L spectrum was 93\% PAR and more concentrated with orange/red (59\%) than green/yellow (20\%) and produces more violet/blue light (14\%). The NS1 spectrum was $94 \%$ PAR and spread between green/yellow (37\%), orange/red (33\%), and violet/blue light (24\%). The percentage of UVA was $1 \%$ in HPS, $0 \%$ in AP673L, and 2\% in NS1. At maturity, plants grown under the two LEDs were shorter and more compact than those grown under HPS due to increased red and blue emission. HPS resulted in higher flower yields (26.6 g per plant) compared to LED treatments (23.1 $\mathrm{g}$ and $22 \mathrm{~g}$ for AP673L and NS1, respectively). These results are comparable to a study by Vanhove et al., (2011), where flower yield per plant was $20.1 \mathrm{~g}$ under similar lighting conditions [29]. The author did not volunteer any explanation for the decreased yield of LEDs-results from other studies imply that the high thermal efficiency of LEDs decreased the overall heat load, thereby reducing temperature and decreasing evapotranspiration rate, net photosynthesis $\left(\mathrm{P}_{\mathrm{N}}\right), \mathrm{CO}_{2}$ assimilation, and, ultimately, yield [22]. Although the dry flower yield ( $\mathrm{g} / \mathrm{plant}$ ) is higher with HPS, it also resulted in the lowest THC mass proportions (9.5\%) while NS1 LED resulted in the highest (15.4\%); this may indicate a positive effect from blue and UV-A light, which was more prominent with NS1 than the other lamps. One alternative explanation is that the low red to far-red light ratio in HPS lamps induced shade avoidance syndrome in plants, reducing phytochemical biosynthesis. Interestingly, despite inducing different morphologies and cannabinoid concentrations, the different lamp treatments did not result in significant differences in total cannabinoid yield (3.2 g/plant for HPS and $4.3 \mathrm{~g} /$ plant for NS1, p > 0.05). LED technology enables the manipulation and optimization of light spectra and could be a useful 
tool for modulating cannabinoid profile and improving yields of specific compounds.

In a recent study, subcanopy lighting (SCL) utilizing LED lights improved cannabis flower quality, consistency, and yield [30]. In this study, plants were not exposed to supplemental SCL or exposed to one of the two kinds of supplemental SCL spectra: red/blue (Red-Blue) and red-green-blue (RGB), positioned $15 \mathrm{~cm}$ to the side of the plant stem and raised $2 \mathrm{~cm}$ off the soil surface during the flowering stage. Both Red-Blue and RGC SCL increased the yield of dry flowers compared to the control due to increased amount of light being delivered to plants. Both Red-Blue and RGCSCL increased yield and concentration of total THC in flowers from the lower plant canopy compared to the control treatment. Red-Blue produced a more homogenous cannabinoid and terpenoid profile throughout the canopy (between the upper and lower canopies).

Light intensity. There is a close relationship between yield and photosynthetic rate [31]. Chandra et al. carried out a series of experiments to study the effects of light intensity, $\mathrm{CO}_{2}$ concentration, and temperature on individual leaves [32] [33] [34]. The $P_{N}$ and water use efficiency (WUE) of a high potency Mexican drug-type variety increased to a point, with increasing PPFD (0, 500, 1000, 1500, and $2000 \mu \mathrm{mol} / \mathrm{m}^{2} / \mathrm{s}$ ) at $20^{\circ} \mathrm{C}$ and $25^{\circ} \mathrm{C}$ [32]. At $30^{\circ} \mathrm{C}$, both $\mathrm{P}_{\mathrm{N}}$ and WUE increased up to $1500 \mu \mathrm{mol} / \mathrm{m}^{2} / \mathrm{s}$ PPFD and decreased at higher light intensities. At higher temperatures $\left(35^{\circ} \mathrm{C}\right.$ and $\left.40^{\circ} \mathrm{C}\right)$, higher PPFD $\left(2000 \mu \mathrm{mol} / \mathrm{m}^{2} / \mathrm{s}\right)$ showed an adverse effect on $\mathrm{P}_{\mathrm{N}}$ and WUE [32]. The rates of transpiration (E) were positively correlated with increasing PPFD and temperature $\left(2000 \mu \mathrm{mol} / \mathrm{m}^{2} / \mathrm{s}\right.$ and $40^{\circ} \mathrm{C}$ ), but leaf stomatal conductance $\left(\mathrm{g}_{\mathrm{s}}\right)$ increased with PPFD up to $30^{\circ} \mathrm{C}$ only [32]. The maximum of $\mathrm{P}_{\mathrm{N}}\left(\mathrm{P}_{\mathrm{Nmax}}\right)$ for this variety was observed at $30^{\circ} \mathrm{C}$ with a PPFD of $1500 \mu \mathrm{mol} / \mathrm{m}^{2} / \mathrm{s}$ [32]. In another study, all four drug varieties from Mexico and Switzerland show increasing $\mathrm{P}_{\mathrm{N}}$ with increasing light intensity with a range of $\left(0,400,800,1200,1600\right.$, and $\left.2000 \mu \mathrm{mol} / \mathrm{m}^{2} / \mathrm{s}\right) \mathrm{PPFD}$ at $25^{\circ} \mathrm{C} \pm 3^{\circ} \mathrm{C}$ [34]. Although the trend of $\mathrm{P}_{\mathrm{N}}$ increasing with PPFD is similar for different varieties, the magnitude of increase and $\mathrm{P}_{\mathrm{N} \max }$ varied considerably with the four varieties studied, with $\mathrm{P}_{\mathrm{Nmax}}$ higher in three Switzerland varieties than one Mexican variety [34]. However, the relationship between higher photosynthesis rate and higher cannabinoid yields has not been conclusively demonstrated [23]. Potter (2009) compared leaf tissue collected from a rare variegated cultivar, which had leaves coloured green and yellow on opposite sides of the midrib, and found that photosynthetic ability has minimal effect on the cannabinoid synthesis on local glandular trichomes [35]. The THC content (w/w\%) of yellow leaf tissue was higher than green leaf tissue on the symmetrically opposite side of the same leaf. To investigate the influence of light intensity on cannabinoids and terpene production, further research is required under controlled environments over a longer term and on whole plants.

When $\mathrm{CO}_{2}$, nutrients, water, and temperature are not limiting factors, dry matter production is proportional to the amount of light intercepted by a crop canopy [36]. Because area is a limiting factor for indoor production, the amount 
of light received per plant is heavily influenced by plant density. With a fixed density, the amount of light received per plant and per square meter is proportional to light intensity at canopy level such that higher light intensity increases yield per plant and per square meter before light saturation occurs. Potter emphasised the close-to-linear correlation between the irradiance level at the commencement of flowering and the subsequent final yield [35]. At the initiation of flowing, the plants maximize light energy usage by developing dense foliar canopies. As a result, increasing PPFD from $78 \mu \mathrm{mol} / \mathrm{m}^{2} / \mathrm{s}$ (converted from $17 \mathrm{~W} / \mathrm{m}^{2}$ of mercury vapour lamps by an conversion factor of 4.59 [37]) to $274 \mu \mathrm{mol} / \mathrm{m}^{2} / \mathrm{s}$ (converted from $55 \mathrm{~W} / \mathrm{m}^{2}$ of HPS lamps by a conversion factor of 4.98 [37]) at plant canopy resulted in a significant increase $(\mathrm{p}<0.01)$ in yield per square meter. A follow-up study measured yield and THC concentrations under PPFD of 400,600 , and $900 \mu \mathrm{mol} / \mathrm{m}^{2} / \mathrm{s}$ (converted from 80,120 , and $180 \mathrm{~W} / \mathrm{m}^{2}$ of HPS lamps by a conversion factor of 4.98 [37]) at the canopy and did not find an increase in concentration at brighter conditions. However, the overall floral THC yield $\left(\mathrm{g} / \mathrm{m}^{2}\right)$ increased because plants in brighter conditions yielded more floral material [38]. In contrast, increasing irradiance did not significantly affect THC concentration or yield in leaf tissue; high light intensity at high temperatures may adversely affect $\mathrm{P}_{\mathrm{N}}$. Additionally, high light intensity is costly. The same study also investigated mean inflorescence yield per unit of electrical powerresults ranged from $0.9,1.2$, to $1.6 \mathrm{~g} / \mathrm{W}$, with the highest yield efficiencies occurring at the lowest power consumption levels $\left(600 \mathrm{~W} / \mathrm{m}^{2}, 400 \mathrm{~W} / \mathrm{m}^{2}, 270 \mathrm{~W} / \mathrm{m}^{2}\right)$. The result was explained by a decreasing tendency for plants to convert light energy into biomass with increasing light saturation at high irradiance levels. This can be used as a reference for licensed producers and individual growers to balance financial input/output when setting up a growing area. A comparison of effects of lighting intensity on the mean yields of dry cannabis flower under different electrical power consumption $\left(400 \mathrm{~W} / \mathrm{m}^{2}, 510 \mathrm{~W} / \mathrm{m}^{2}, 600 \mathrm{~W} / \mathrm{m}^{2}\right)$ in four published European studies suggested that the mean yield of dry cannabis flower is approximately $1 \mathrm{~g} / \mathrm{W}$, while electrical energy consumption per gram of yield averaged approximately $1 \mathrm{kWh} / \mathrm{g}$ from planting to harvest [39].

With the same light output and room size, increasing plant density beyond a certain point decreases light interception per plant, resulting in decreased yield per plant, but the total room yield remains constant. One study investigated two light intensities (one $600 \mathrm{~W}$ HPS lamp per square metervs. one $400 \mathrm{~W}$ HPS lamp per square meter), two plant densities ( 16 plants $/ \mathrm{m}^{2}$ density vs. 20 plants $/ \mathrm{m}^{2}$ ), and four varieties in a total of sixteen scenarios. It concluded that all three factors significantly affect yield per plant; however, plant density had no effect on yield per square meter [29]. This indicates that light interception is the limiting factor for total indoor yield. Specifically, yield per plant increased with light wattage, decreased with density, and was significantly different between cultivars. Similar observations were made on yield per area, except that yield per area is independent of plant density. Based on these results, light intensity and plant density are considered as independent additive factors. This topic is of interest to 
industrial growers, and studies are required to determine the optimized combination of light intensity with plant population to fully utilize light and space resources to maximize yield and profitability. However, there must exist upper and lower thresholds at which plant density will affect yield per area, either in extreme overcrowding or sparseness situations. Such thresholds have not been investigated.

Light regime. Cannabis is a "short-day" plant that naturally flowers in late summer [40], where it needs uninterrupted and sufficiently long nights to initiate flowering. This process is regulated by a class of photoreceptors in the plants called phytochromes [41]. Phytochromes exist as two photoreversible forms: the red light absorbing form $\left(\mathrm{P}_{\mathrm{r}}\right)$ and the far-red light absorbing form $\left(\mathrm{P}_{\mathrm{fr}}\right)$, the latter of which inhibits flowering [41]. In the dark, the active form $\mathrm{P}_{\mathrm{fr}}$ slowly reverses back to the state form $\mathrm{P}_{\mathrm{r}}$, but the fewest photons of a flash red light with a peak near $667 \mathrm{~nm}$, which is found in both daylight and lamp light, can convert the $\mathrm{P}_{\mathrm{r}}$ to $P_{\text {frr }}$, subsequently, inhibits flowering [35] [41]. For indoor cultivation, a regimen of 18 hours or 24 hours of continuous light has been used for vegetative growth. A schedule of 12 hours of light and 12 hours of darkness is considered a short day length, and has been widely utilized to initiate flowering-the first flowers are visible one week after the light schedule change [12]. The critical day time length is related closely with a variety's geographical origin, especially those originating far from the equator [35]. Because day time in all latitudes in the North Hemisphere is longer than 12 hours at summer solstice, 12 hours of darkness will initiate flowering for most varieties. Eleven hours of darkness initiated flowering in tropical varieties, possibly due to plant age instead of light regimen [35].

The effect of light regimen on plant development and cannabinoids profile were studied by Potter by subjecting dozens of cannabis varieties (clone lines) to either 11, 12 or 13 hours of light (short day length) after three weeks of vegetative growth under continuous light for 24 hours [35]. The first part (comparison of 12 and 13 hour of light) of the study was carried out in glasshouses while the second part (comparison of 11 and 12 hours of light) was carried out in an indoor environment. The results are summarized in Table 1. The yield of total floral and foliage material of plants was referred to as Botanical Raw Material (BRM) yield $\left(\mathrm{g} / \mathrm{m}^{2}\right)$. The mean BRM yield $\left(\mathrm{g} / \mathrm{m}^{2}\right)$ and the cannabinoid yield $\left(\mathrm{g} / \mathrm{m}^{2}\right)$ of plants was significantly higher when grown under 12 hours of light compared to 11 hours. There was no benefit in increasing from 12 to 13 hours of light, but there were large decreases in yield in decreasing from 12 to 11 hours of light. Therefore, a 12-hour light regime is the most energy-efficient and economical [35]. It is notable that although there is no significant difference in mean values of all clone lines of some effects investigated, for example, the mean height, the total floral and foliage material $\left(\mathrm{g} / \mathrm{m}^{2}\right)$, and the cannabinoid yield $\left(\mathrm{g} / \mathrm{m}^{2}\right)$, these effects varied with individual clone lines (strains). Each strain requires unique growing conditions and harvest timings that should be investigated and optimized within its specified growing environment. 
Table 1. The effect of light regimen on plant development and cannabinoids profile.

\begin{tabular}{|c|c|c|c|c|c|c|c|c|}
\hline \multirow[b]{3}{*}{ Light regimen } & \multicolumn{4}{|c|}{ Glasshouse (10 clone lines) } & \multicolumn{4}{|c|}{ Indoor/Artificial Light (12 clone lines) } \\
\hline & \multicolumn{2}{|c|}{ Eight weeks in short light } & \multicolumn{2}{|c|}{ Ten weeks in short light } & \multicolumn{2}{|c|}{ Eight weeks in short light } & \multicolumn{2}{|c|}{ Ten weeks in short light } \\
\hline & 12 hours & 13 hours & 12 hours & 13 hours & 11 hours & 12 hours & 11 hours & 12 hours \\
\hline Proportion of senesced stigmas & Higher & Lower & Higher & Lower & $\mathrm{NSD}^{a}$ & NSD & NSD & NSD \\
\hline Mean height of all clone lines & NSD & NSD & Shorter & Taller & NSD & NSD & NSD & NSD \\
\hline Mean yield of BRM $\left(\mathrm{g} / \mathrm{m}^{2}\right)$ & NSD & NSD & NSD & NSD & Lower & Higher & Lower & Higher \\
\hline Cannabinoid yield $\left(\mathrm{g} / \mathrm{m}^{2}\right)$ & NSD & NSD & NSD & NSD & - & - & Lower & Higher \\
\hline $\begin{array}{l}\text { Proportional CBG content } \\
\text { (CBG as \% of } \mathrm{CBG}+\mathrm{THC})\end{array}$ & Lower & Higher & Lower & Higher & NSD & NSD & NSD & NSD \\
\hline $\begin{array}{l}\text { Proportional THCV content } \\
\text { (THCV as } \% \text { of THCV + THC) }\end{array}$ & Higher & Lower & Higher & Lower & - & - & - & - \\
\hline
\end{tabular}

${ }^{a}$ No significant difference $(p>0.05)$.

Light cycle in the vegetative stage. Under a continuous light regimen of 24 or 18 hours of light per day, cannabis plants remain vegetative. Vegetative growth shifts to reproductive growth after a two week exposure to 12 continuous hours of light per day [12]. Cuttings from a THC dominant variety were grown indoors by Bedrocan VB (Netherlands) under $18 \mathrm{~h}$ of light for 37 days of vegetative stage and $12 \mathrm{~h}$ of light for 40 days of flowering stage [42]. One batch was grown under standard conditions and other three batches were grown with one less week of vegetative growth plus one extra week of flowering, one extra week of vegetative growth, one extra week of vegetative growth and one extra week of flowering, respectively. Differences were observed in certain compounds compared with the standard batch. The conclusion was that alterations in growth cycle time appear to cause more differences in chemical profile than growing cuttings in different batches [42].

Light cycle in the flowering stage. A recommended growth period for 200 indoor high-THC cannabis varieties from 20 producers in Europe is between seven to nine weeks in short day length, with a mean recommended duration of 57 days [39]. In order to study the effect of duration of flowering period on cannabinoid yield, 25 THC-dominant clone lines from 14 varieties were sampled in the GM Pharmaceuticals' glasshouses at the sixth, eighth, and tenth weeks flowering [35]. With a 33\% extension in flowering duration from the sixth to eighth week, mean THC yield $\left(\mathrm{g} / \mathrm{m}^{2}\right)$ increased over $50 \%$. With $25 \%$ extension in flowering period from the eighth to ten weeks, mean THC yield $\left(\mathrm{g} / \mathrm{m}^{2}\right)$ increased $30 \%$, while the yield increases for approximately half of the clones were less than $25 \%$. The mean THC and CBG content in floral and foliage material continuously increased in the twenty-five clones between the sixth and tenth week of flowering, while the mean proportion of CBG fell as a proportion of total THC and CBG. This suggests that the ratio of these two cannabinoids can be affected by harvest timing. Furthermore, genetics impact THC:CBG ratios more than harvest timing because the THC:CBG ratio of one clone was stable at all harvest 
timings whereas the average THC:CBG ratios combined from three harvest dates (six, eight, ten weeks) showed significant differences between clone lines. The effect of flowering period length on mixed THC/CBD profiles were studied on five clone lines from five seeds of one variety. THC and CBD content in floral and foliage material continuously increased from the fourth week to eighth week in 12-hour light regime but stopped increasing after the ninth week. For one of the clone lines, the $\mathrm{CBD} / \mathrm{THC}$ ratio remained constant over the entire flowering stage whereas the ratio fluctuated in other clone lines. Potter concluded that the clone lines with stable $\mathrm{CBD} / \mathrm{THC}$ ratio can be used as phytopharmaceutical feedstocks and, if such clones are absent, desirable consistent cannabinoid mixtures could only be achieved by blending materials possessing one single dominant cannabinoid. THC dominant Sativex plants grown in the GM Pharmaceuticals' glasshouses were normally harvested at eight weeks after switch to a 12-hour light regime. While the THC content in floral tissue was relatively stable (13\% - 17\%) between the fourth week and ninth week with highest value achieved around six weeks in short day length, the floral yield per plant increases steadily until the end of cultivation, which is $400 \mathrm{~g} / \mathrm{m}^{2}$ of floral material combined with $200 \mathrm{~g} / \mathrm{m}^{2}$ of foliage material.

Another study concluded that the peak total THC content (THC + THCA) in floral material was achieved between the sixth and seventh week after changing to a 12-hour regime in an indoor grow box and the total THC content started to decline at the onset of senescence in all three chemotype I varieties [35]. Aizpurua-Olaizola (2016) observed that plants from chemotypes II and III needed more time to reach peak production of THCA, CBDA, and monoterpenes than plants from chemotype I [17]. Clones from all chemotypes were kept for 42 days for root-growing phase, followed by 60 days for vegetative stages under 18 hours of light and 77 days for flowering phase under 12 hours of light [17]. THCA in flowers of chemotype I plants peaked at the ninth week in short day length (day 165) for indoor growth, while peak content of THCA and CBDA in chemotype II (THC and CBD with equivalent ratio) and chemotype III (CBD dominant) continued to increase until the end of the study (eleventh week, or day 179). The total amount of eight monoterpenes in flowers reached its peak in the ninth week of the flowering phase for chemotype I while the levels continued to increase until the end of the study for chemotype II and III. The amount of sesquiterpenes was stable during the flowering phase. Different maxima may depend on cultivars, cultivation method (from seed or clone), and growing environment (lighting, temperature, humidity, growing medium, nutrients, etc.).

Temperature. Temperature can be a limiting factor for $\mathrm{P}_{\mathrm{N}}$ : Low temperatures slow $\mathrm{P}_{\mathrm{N}}$ and excessive heat stops $\mathrm{P}_{\mathrm{N}}$. High temperature causes plants to expend energy in cooling by acquiring water and transpiring it through the stomata. Chandra (2011) studied $\mathrm{P}_{\mathrm{N}}$ in seven cannabis varieties and concluded that the optimal temperatures varied between $25^{\circ} \mathrm{C}$ to $30^{\circ} \mathrm{C}$ and were variety-specific [33]. The optimum growth temperature is $25^{\circ} \mathrm{C}-30^{\circ} \mathrm{C}$ for tropical varieties and $25^{\circ} \mathrm{C}$ for temperate varieties [2]. In a field experiment on industrial hemp, Sikora 
calculated accumulative growing degree days (GDD) instead of daily temperatures and found that THC and CBD concentrations are positively correlated with GDD [43]. However, the authors assumed a linear relationship between climate and the content of major cannabinoids, resulting in poor statistical regression between GDD and THC \& CBD content. Four varieties from both temperate (Illinois and Nepal) and tropical (Jamaica and Panama) climates yielded higher THC content ( $\mathrm{mg} / \mathrm{g}$ dry weight) in cannabis leaves under cool conditions $\left(23^{\circ} \mathrm{C}\right)$ than under warm conditions $\left(32^{\circ} \mathrm{C}\right)[44]$.

$\mathrm{CO}_{2}$ concentration. Carbon dioxide $\left(\mathrm{CO}_{2}\right)$ is one of the two limiting factors for $\mathrm{P}_{\mathrm{N}}$. A high potency Mexican drug-type variety was exposed to different concentrations of $\mathrm{CO}_{2}(250,350,450,550,650$, and $750 \mu \mathrm{mol} / \mathrm{mol})$ under optimum lightning and temperature conditions $\left(30^{\circ} \mathrm{C}\right.$ and $1500 \mu \mathrm{mol} / \mathrm{m}^{2} / \mathrm{s}$ PPFD) [32]. Elevated $\mathrm{CO}_{2}$ concentration $(750 \mu \mathrm{mol} / \mathrm{mol})$ increased $\mathrm{P}_{\mathrm{N}}$, WUE, and intercellular $\mathrm{CO}_{2}$ concentration $\left(\mathrm{C}_{\mathrm{i}}\right)$ by $50 \%, 111 \%$, and $115 \%$ respectively and suppressed the rate of transpiration $\mathrm{E}$ and $\mathrm{g}_{\mathrm{s}}$ by $29 \%$ and $42 \%$ respectively compared to ambient $\mathrm{CO}_{2}\left(\mathrm{C}_{\mathrm{a}}: 350 \mu \mathrm{mol} / \mathrm{mol}\right)$ [32]. Higher $\mathrm{P}_{\mathrm{N}}$, WUE, and nearly constant $\mathrm{C}_{\mathrm{i}} / \mathrm{C}_{\mathrm{a}}$ under elevated $\mathrm{CO}_{2}$ concentrations suggested a potential for better survival, growth, and productivity in $\mathrm{CO}_{2}$ rich environments [32].

Humidity. Compared to relative or absolute humidity, vapor pressure deficit (VPD) more accurately describes the driving force of water loss from plant leaves. VPD combines the relative humidity and air temperature and describes the difference between the actual and maximum amounts of water the air can hold for a given temperature. VPD impacts the opening of leaf stomata, which are responsible for $\mathrm{CO}_{2}$ and water vapor exchange, thereby affecting $\mathrm{P}_{\mathrm{N}}$ and nutrient transportation. High VPD may induce wilt and necrosis of the leaf tips. For indoor cultivation, ventilation is crucial to control humidity because both high and low VPD can result in reduced yield [22]. At a growing temperature of $25^{\circ} \mathrm{C}$, the recommended relative humidity is $75 \%$ for juvenile cannabis plants and $55 \%-60 \%$ for vegetative growth and flowering [45], which correspond to $\mathrm{VPD}$ of $0.8 \mathrm{kPa}$ and $1.3-1.4 \mathrm{kPa}$ respectively. VPD is calculated using the following formula [46]:

$$
\mathrm{VPD}=(1-R H) \times 610.7 \times 10^{\frac{7.5 T}{237.3+T}}
$$

where $T$ is the atmospheric temperature in centigrade and $R H$ is relative humidity.

A review of several works reported an increased THC content in drier climates, which was explained as an enhanced THC production in response to stress [27]. A recent experiment confirmed that controlled drought stress may be an effective horticultural management technique to maximize both floral weight and cannabinoid yield in cannabis [47]. An eleven-day drought (withholding irrigation until the drought stress threshold of $-1.5 \mathrm{MPa}$ was reached at week seven of the flowering stage) increased the concentration of major cannabinoids THCA and CBDA by $12 \%$ and $13 \%$, respectively. In Chemotype II plants, yield per unit growing area of THC was $43 \%$ higher, CBDA yield was $47 \%$ higher, 
THC yield was 50\% higher, and CBD yield was $67 \%$ higher than the control. A follow-up investigation directly contradicted these results: drought stress timing and frequency (in weeks four, five, six, or seven weeks in the flowering stage) did not result in higher floral yield or cannabinoid content compared with the control [47]. The author attributed the differences to the container size and growing medium-the follow-up study used larger growing vessels than the previous trial, so it took longer for a plant to deplete the water already in the vessel to achieve drought conditions. The timing of controlled drought stress was found to influence the content of some terpenoids. Earlier drought stress increased the yield of linalool and cis-ocimene but decreased yield of caryophyllene. Later drought stress increased the yield of alpha-bisabolol and trans-ocimene.

Growing medium. Both soil and soilless (i.e. hydroponics) mediums are used for cannabis production. AHP recommends neutral to alkaline loamy and sandy soil with a pH between 6.5 and 7.2 [2]. One study grew cannabis in eleven different soils that varied in $\mathrm{pH}$ and elemental composition [48]. Soil parameters were correlated with the leaves' elemental and cannabinoid contents. Extractable soil Mg was negatively correlated with THC and CBD concentrations in leaf tissue. Extractable soil $\mathrm{P}$ was negatively correlated with $\mathrm{CBD}$ concentrations in leaf tissue [48]. Another study showed that there was no difference in floral material yield between two organic coir-based growing media, which had distinct water-holding capacities [49]. However, the lower capacity (U2-HP) growing medium produced $11 \%$ higher floral dry weight, 13\% higher growth index, 20\% higher THC yield, and 20\% higher CBGA yield than the one with higher capacity (U2) [49]. The increases may be attributed to the higher irrigation frequency (17 times in U2-HP and 13 times in U2), which was necessary for maintaining moisture $(30 \%)$, and/or high root zone oxygen, which positively affects plant health, nutrient uptake, root growth, and root-bone disease prevention [49]. Hydroponic systems have greater control over the growing environment by delivering a full range of nutrients to the roots. Active hydroponic systems use pumps and include ebb and flow systems, nutrient film technique, drip irrigation, aeroponics, and deep-water-culture systems. Passive systems use capillary action to drag water to the roots and these include reservoir systems, wick systems, and capillary mats. Commonly used growing media for hydroponic systems include light expanded clay aggregate (referred to as LECA), rock wool, and coconut fibre (coir).

Both soil and hydroponics are widely used for commercial cultivation, and each has its own advantages and disadvantages. Soil has a greater buffer capacity than hydroponics and is simpler to set up. Hydroponic systems allow for comprehensive control, enabling quicker and easier troubleshooting for nutrient delivery. With easy access to nutrients and water, plants are commonly believed to grow faster and have higher yields with hydroponics. However, evidence suggested that yields and potency are not improved by hydroponics compared to soil systems [39]. In addition, a hydroponics system is more complex and requires constant availability of water, electricity, nutrients, and other supplies. 
The increased complexity without corresponding increases in cannabis productivity or potency led to GW Pharmaceuticals' rejection of hydroponic growing systems in the Netherlands [12].

\subsection{Management Practices}

\section{Starting materials}

Seeds vs. clones. Two starting materials are available: seeds and clones. Clones are made from tissue cultures by micropropagation or from cuttings of a mother plant. Clones guarantee genetic uniformity, which the pharmaceutical industry values for consistency of quality, safety, and efficacy-qualities that the industry regards as more important than high yield [12]. Clones can also avoid the development of male plants that can be encountered when starting from seeds [2]. To compare the yield and uniformity of plants grown from seeds and clones, Potter grew thirty plants from cuttings and thirty plants from seeds of one variety under identical environmental conditions. The yield of floral and foliage material obtained from plants grown from seeds $\left(494 \mathrm{~g} / \mathrm{m}^{2}\right)$ and those grown from cuttings $\left(515 \mathrm{~g} / \mathrm{m}^{2}\right)$ were not significantly different $(\mathrm{p}>0.05)$. However, the mean THC content of the cloned plants (14.6\% THC w/w) was significantly higher than those grown from seeds $(11.1 \% \mathrm{THC})(\mathrm{p}<0.01)$. Although the mean $\mathrm{CBG}$ and $\mathrm{CBC}$ content in floral and foliage has no significant differences ( $\mathrm{p}>$ 0.05 ) from plants grown from seeds and grown from cuttings, the CBC potency of seed derived plants was significantly more variable $(\mathrm{p}<0.01)$. The ratios of cannabinoids were also found to be significantly more variable in plants grown from seeds $(\mathrm{p}<0.01)$. However, it was not discussed whether the variability resulted from the uniformity of the heterozygous seeds or homozygous seeds. Furthermore, to achieve maximum rooting success and root quality, cuttings from either apical or basal positions $(p>0.05)$ should have at least three fully expanded (compared with having two leaves) and uncut leaves (compared with removing the leaf tip), and treated with $0.2 \%$ indole-3-butyric (IBA) rooting hormone (compared with treating with $0.2 \%$ willow extract gel) [47]. Among these factors, rooting hormone had the greatest effect on both rooting success rate and root quality while removing leaf tips had the second greatest effect on rooting success rate.

Irrigation. Water quality is critical for $\mathrm{P}_{\mathrm{N}}$ and its products and nutrient transport. For greenhouse crops, the water should be absent of contamination from metals, herbicides, pesticides, and toxicologically hazardous substances [21]. In addition, irrigation water should be tested for the following desirable parameters: alkalinity (expressed as $\mathrm{CaCO}_{3}$ concentration), $\mathrm{pH}$, and electrical conductivity (EC) [50]. The recommended parameters vary greatly among different strains. The optimal EC or $\mathrm{pH}$ for cannabis in soil or hydroponic systems has yet to be established through experimentation. General recommendations for irrigation are $\mathrm{CaCO}_{3}$ concentrations between $30 \mathrm{mg} / \mathrm{L}$ and $100 \mathrm{mg} / \mathrm{L}$, EC below $1.5 \mathrm{mS} / \mathrm{cm}$, and hardness as $\mathrm{Ca}$ and $\mathrm{Mg}$ ions between $100 \mathrm{mg} / \mathrm{L}$ to $150 \mathrm{mg} / \mathrm{L}$ [51]. AHP recommends that the $\mathrm{pH}$ in irrigation water should be $6.5-7.2$ for soil and $5.8-6.0$ 
for hydroponics [2]. The $\mathrm{pH}$ should be continuously monitored and adjusted whenever it deviates from the set point. Watering frequency and amount can be visually determined or automated to satisfy plant requirements [12] [52] [53].

Nutrient supply. If the growing medium lacks nutrients, it must be supplemented to ensure the plants' health and yield. Different fertilizers may be used or mixed in accordance with different growth cycles, however, organic fertilizers are not recommended for hydroponic systems because they ferment in the reservoirs, causing microbiological contamination and clogging.

Several studies analyzed the effect of applied fertilizers on morphological and biochemical characteristics of cannabis plants. One study analyzed responses of greenhouse-grown cannabis to $\mathrm{N}, \mathrm{P}$, and $\mathrm{K}$ at low (0 ppm), medium (25 ppm for $\mathrm{N}$ and $50 \mathrm{ppm}$ for $\mathrm{P}$ and $\mathrm{K}$ ), and high concentrations (125 ppm for $\mathrm{N}$ and 150 ppm for P and K) [54]. Fertilizers were applied during planting. Mean height (at 28 days and harvest) and tissue yield (combined leaves and flowers) were positively correlated with applied $\mathrm{P}$ at three concentrations but were not statistically significant for applied N or K. Although THC and CBD concentrations showed no significant differences after treatment with applied $\mathrm{P}, \mathrm{N}$, and $\mathrm{K}(\mathrm{p}>0.05)$, total THC yield was significantly positively correlated with applied $\mathrm{P}$ due to increased biomass $(\mathrm{p}<0.05)$. In a study where three levels of $\mathrm{N}$ fertilizer were applied once each month with totals of 150,450 , and $600 \mathrm{mg} / \mathrm{kg}$, applied $\mathrm{N}$ had a positive effect on plant height and a negative effect on THC content (\% dry weight) in leaves [55]. $\mathrm{Mg}$ and Fe were reported to be important for THC production as enzyme co-factors [27].

Caplan sought to determine the optimal rate of organic fertilizer during vegetative and flowering stages for cannabis grown in coir-based growing media. The study applied liquid fertilizer with a N-P-K ratio of 4:1.3:1.7 at rates of 117, 234, 351,468 , and $585 \mathrm{mg}$ nitrogen per litre of irrigation water (N/L) during vegetative growth and found that the interpolated optimal rate was $389 \mathrm{mg} \mathrm{N} / \mathrm{L}$. This optimal rate increased the yield of floral dry weight by $80 \%$ as compared to 117 $\mathrm{mg}$ N/L [49]. The final yield was positively correlated with growth attributes (growth index [height $(\mathrm{cm}) \times$ length $(\mathrm{cm}) \times$ width $(\mathrm{cm}) \times 300^{-1}$ ], leaf number, and branch number) in the vegetative stage [49]. This result suggests that growing larger plants during the vegetative stage by supplying optimal fertilizer rate will increase yield [49]. The study also concluded that fertilization rate had no effect on floral THCA concentrations $(10.6 \% \pm 0.31 \%)$ or CBN concentrations $(0.08 \% \pm 0.018 \%)$ but increased THC concentrations, reaching a maximum of $0.31 \%$ at $418 \mathrm{mg} \mathrm{N} / \mathrm{L}$ [49]. Optimal fertilization during the vegetative stage may reduce maturation time [49].

The same study applied five rates of liquid organic fertilizer (57, 113, 170, 226, and $283 \mathrm{mg} \mathrm{N} / \mathrm{L}$ ) with a N-P-K ratio of 2.00:0.87:3.32 during the flowering stage in two coir-based growing media [49]. Fertilizer rate was positively correlated with floral yield. In the medium with lower water-holding capacity (U2-HP), the interpolated optimal rate $(261 \mathrm{mg} \mathrm{N} / \mathrm{L}$ ) increased the yield of floral dry weight by $110 \%$ compared to the lowest rate $(57 \mathrm{mg} \mathrm{N} / \mathrm{L}$ ). Similar results were found for 
the other medium. Although growth and floral yield are increased with fertilizer rate, concentrations of THC, THCA, and CBGA decreased. The optimal fertilizer rate for U2-HP for maximizing both floral yield and cannabinoid yield was between 212 and $261 \mathrm{mg} \mathrm{N} / \mathrm{L}$.

Growing medium management. The condition of the growing medium is dependent on the primary inputs: irrigation and fertilization. Caplan's experiment showed that growing medium $\mathrm{pH}$ decreased over time for all fertilizer rates applied during vegetative growth [49]. The highest floral yield, which supplied 234, 351 , and $468 \mathrm{mg} \mathrm{N} / \mathrm{L}$, resulted in the lowest $\mathrm{pH}$ values, which were between 6.19 and 6.5, with lowest mean $\mathrm{pH}$ (6.19) occurring at $351 \mathrm{mg} \mathrm{N} / \mathrm{L}$ rate on day 17 [49]. The low $\mathrm{pH}$ values for organic fertilizers may be caused by $\mathrm{NH}_{4}^{+}$nitrification and the excretion of protons by the roots after $\mathrm{NH}_{4}^{+}$uptake [49]. This study showed no visual signs of nutrient disorders with $\mathrm{pH}$ between $6.2-7.1$ for the vegetative stage and $6.7-7.2$ for the flowering stage. EC was positively correlated with fertilization, ranging from 0.9 to $3.9 \mathrm{mS} / \mathrm{cm}$ [49]. Floral yield was reduced at 468 and $585 \mathrm{mg} \mathrm{N} / \mathrm{L}$, and was attributed to high EC, which was $3.0 \pm$ 0.13 and $3.8 \pm 0.13 \mathrm{mS} / \mathrm{cm}$, respectively. Salinity is expressed in EC and can lead to increased osmotic potential and reduced external water potential in the root zone. The $\mathrm{pH}$ decreased and EC increased upon higher rates of fertilizer application during flowering [49]. The study concluded that cannabis tolerates EC up to $3.0 \mathrm{mS} / \mathrm{cm}$ without reductions in yield.

Pruning and training. Pruning and training enhance yield by maximizing light interception, optimizing nutrient allocation, creating more air circulation, and reducing humidity. Clipping the lower branches on the Bedrocan variety (hybrid "Indica"/“Sativa"), which were grown under 37 days of vegetative stage and 54 days of flowering stage, resulted in lower concentrations for THC, CBG and some terpenes [42]. Additional studies need to be conducted to quantitatively determine the effects of pruning timing and amount on growth and yield.

Another technique uses framed netting to support and position buds in an "opened-up" gesture to provide more light to the lower branches. Knight utilized the ScrOG method, which uses framed netting, to enhance yield of an indoor hydroponic system [56]. An average of $687 \mathrm{~g}$ dried inflorescence was achieved per plant using this method. This relatively high yield per plant maybe due to the characteristics of the strains selected and the relatively low plant density (6 plants in $15 \mathrm{~m}^{2}$ ). The estimated yield per area was $274.8 \mathrm{~g} / \mathrm{m}^{2}$ and was comparable to yields reported in other studies [39].

Harvest timing. Because the content of cannabinoids and terpenes change throughout growing and flowering stages, harvest timing affects final chemical composition. To determine specific harvest timing, two methods are commonly used by growers: chemical analysis and visually observation/organoleptic evaluation. The University of Mississippi checks THCA concentrations of raw materials daily to determine optimal harvest time [2]. Whereas chemical analysis is destructive, visual examination is adopted to set harvest timing without disturbing the plants. AHP suggests four physical evaluations. The first evaluation is based 
on the percentage of senesced stigmas, which appear brown. The percentage at harvest is suggested as $75 \%$ [18]. The second evaluation is based on the firmness of the inflorescence-relatively firm resistance when pressed suggested maturity. The third evaluation is based on the color of glandular trichomes. Harvest should occur when there is a shift from a clear to amber or a cloudy white of the first resin heads, which indicates the degradation of THC to CBN. The last evaluation is based on odor, which will reach a peak and give a unique and strain-specific pungent aroma at maturity. These methods can be combined to determine optimal harvest timing [2].

\subsection{Post-Harvest}

After harvesting cannabis, it is manicured, cured, dried, and stored. Fresh cannabis material typically contains $78-80 \%$ moisture [39] and drying is necessary for handling, storage, and avoiding degradation of major cannabinoids before chemical examination. The Office of Medicinal Cannabis of the Dutch Government specifies that the water content of cannabis must be between 5\% - 10\% directly after packing [57]. Drying crops directly on the ground or under direct sunshine must be avoided [21]. Plants dry within 24 hours to $15 \% \pm 2 \%$ moisture when spread evenly to a depth of approximately $15 \mathrm{~cm}$ at $40^{\circ} \mathrm{C}$ [35]. Moisture content can be checked by measuring weight loss after drying for 24 hours at $105^{\circ} \mathrm{C}$. If the plants are hung to dry, the mean times taken to achieve $15 \%$ moisture were 36,18 , and 11 hours at $30^{\circ} \mathrm{C}, 40^{\circ} \mathrm{C}$, and $50^{\circ} \mathrm{C}$, respectively [35]. When stored in paper bags to dry at $21^{\circ} \mathrm{C}$ and $40 \% \mathrm{RH}$, fresh floral material cut from stems reached $11 \% \pm 1 \%$ moisture in 5 days [47]. The dried material was then cured at $18^{\circ} \mathrm{C}$ and $60 \% \mathrm{RH}$ for 14 days before determining the floral dry weight [47]. Drying at temperature higher than $37^{\circ} \mathrm{C}$ for 24 hours may decarboxylate cannabinoid acids [58]. The effect of high drying temperatures on cannabinoids and terpenes requires further investigation. To minimize loss of volatile terpenes during heating, another method for cannabinoid and terpene preservation is freezing by sublimation, which takes 10 to 20 days.

As oxidation occurs with the presence of light, heat, and oxygen, degradation of major cannabinoids is minimized after drying by storage in cool and dark places. Fresh products must be stored between $1^{\circ} \mathrm{C}$ and $5^{\circ} \mathrm{C}$ and frozen products must be kept at $-18^{\circ} \mathrm{C}$ to $-20^{\circ} \mathrm{C}$ for long-term storage [21]. The content of THC stored at $-18^{\circ} \mathrm{C}, 4^{\circ} \mathrm{C}$, and $22^{\circ} \mathrm{C} \pm 1^{\circ} \mathrm{C}$ decomposed at rates of $3.83 \%, 5.38 \%$, and $6.92 \%$ per year, respectively [59]. Samples can be stored at $-18^{\circ} \mathrm{C}$ or $4^{\circ} \mathrm{C}$ for about 30 weeks before concentrations of THCA and THC change, however, samples stored at $22^{\circ} \mathrm{C} \pm 1^{\circ} \mathrm{C}$ showed some immediate decomposition. Dried samples stored at $50^{\circ} \mathrm{C}$ for 24 hours showed slight decarboxylation while those stored at $100^{\circ} \mathrm{C}$ and $150^{\circ} \mathrm{C}$ showed significant decarboxylation of THCA and decomposition of THC within two hours [60]. The effect of freeze-drying on terpenes has not been well-studied, but reportedly fails to preserve the profile of the fresh plant by changing terpene concentrations [61]. 


\section{Conclusions}

Cannabis standardization is required to obtain consistent cannabinoid and terpene profiles and, subsequently, stable efficacy for medical purposes. Growing conditions and management practices should be optimized and standardized to maximize yields; light, temperature, $\mathrm{CO}_{2}$ concentration, irrigation, humidity, nutrients, and growing media combine and interact to affect the final yield.

The effects of LED should be compared with traditional lamps used in cannabis cultivation in terms of cannabis yield and electricity consumption. The effects of near-visible light, especially UV, on yield require additional data to form conclusions. Light intensity studies have been conducted with conclusive results, but comparisons between studies are hampered by the differences in controlled variables between experiments. Optimal light conditions for cannabis should be researched under controlled environments to determine the optimized combination of light intensity with plant density for maximum plant yield. Light interception and plant growing density may affect the development rate of inflorescences, however, current research yields conflicting results. Optimal growing temperatures for cannabis are believed to be associated with the cultivars' geographic origins. Studies that control for temperature are lacking.

The $\mathrm{pH}$ value recommendations in growing media vary in current literature. Watering amount and frequency is not well specified. Fertilizers have many variables and the effects of content, elemental ratio, and frequency of fertilization on yield are unclear. Analyzing the effects of the dozens of interacting variables of the nutrient in growing media will be a significant undertaking and will require large amounts of indoor growing space to control for individual variables. Studies comparing the yield and quality of cannabis cultivation in soil and hydroponic systems are still lacking.

Details on pruning and training are limited. The effects of different pruning and training techniques, including pruning lower leaves during vegetative stage, clipping or inverting the top to make the plant bushy, utilization of framed netting or ScrOG methods needs to be examined in controlled studies. Harvest timing is subjective and must be examined on a case-by-case basis. Due to the large number of variables, it may not be possible to determine exact harvest times for cannabis. The fluctuation of cannabinoids and terpenes throughout a 24-hour cycle needs further research. Post-harvest treatment, especially drying temperature and duration, should be studied for the effects on cannabinoids and terpene loss.

Current industrial practices for growing conditions vary significantly, and certain aspects of harvest can be subjective. Additional research and studies are required to conclusively develop a set of optimal and standardized growing conditions and harvest techniques.

\section{Acknowledgements}

The authors acknowledge Labs-Mart Inc. for providing funding during the 
preparation of this manuscript. We are also grateful to Dr. Tiequan Zhang from Agriculture and Agri-Food Canada and Dr. Thomas Graham from the University of Guelph for providing valuable comments and suggestions.

\section{Conflicts of Interest}

The authors declare no conflicts of interest regarding the publication of this paper.

\section{References}

[1] ElSohly, M.A., Gul, W., Wanas, A.S. and Radwan, M.M. (2014) Synthetic Cannabinoids: Analysis and Metabolites. Life Sciences, 97, 78-90.

https://doi.org/10.1016/j.lfs.2013.12.212

[2] Upton, R., Craker, L., ElSohly, M., Romm, A., Russo, E., Sexton, M., et al. (2013) Cannabis Inflorescence: Cannabis Spp.; Standards of Identity, Analysis, and Quality Control. American Herbal Pharmacopoeia, Scotts Valley, CA.

[3] Taura, F., Morimoto, S., Shoyama, Y. and Mechoulam, R. (1995) First Direct Evidence for the Mechanism of Delta-1-Tetrahydrocannabinolic Acid Biosynthesis. Journal of the American Chemical Society, 117, 9766-9767. https://doi.org/10.1021/ja00143a024

[4] Taura, F., Morimoto, S. and Shoyama, Y. (1996) Purification and Characterization of Cannabidiolic-Acid Synthase from Cannabis sativa L.: Biochemical Analysis of a Novel Enzyme That Catalyzes the Oxidocyclization of Cannabigerolic Acid to Cannabidiolic Acid. Journal of Biological Chemistry, 271, 17411-17416. https://doi.org/10.1074/jbc.271.29.17411

[5] Morimoto, S., Komatsu, K., Taura, F. and Shoyama, Y. (1997) Enzymological Evidence for Cannabichromenic Acid Biosynthesis. Journal of Natural Products, 60, 854-857. https://doi.org/10.1021/np970210y

[6] Fellermeier, M. and Zenk, M.H. (1998) Prenylation of Olivetolate by a Hemp Transferase Yields Cannabigerolic Acid, the Precursor of Tetrahydrocannabinol. FEBS Letters, 427, 283-285. https://doi.org/10.1016/S0014-5793(98)00450-5

[7] Fellermeier, M., Eisenreich, W., Bacher, A. and Zenk, M.H. (2001) Biosynthesis of Cannabinoids. Incorporation Experiments with ${ }^{13} \mathrm{C}$-Labeled Glucoses. European Journal of Biochemistry, 268, 1596-1604. https://doi.org/10.1046/j.1432-1327.2001.02030.x

[8] Hazekamp, A. (2007) Cannabis: Extracting the Medicine. Print Partners Ipskamp, Amsterdam.

[9] Russo, E.B. (2011) Taming THC: Potential Cannabis Synergy and Phytocannabinoid-Terpenoid Entourage Effects. British Journal of Pharmacology, 163, 1344-1364. https://doi.org/10.1111/j.1476-5381.2011.01238.x

[10] Jin, D., Jin, S., Yu, Y., Lee, C. and Chen, J. (2017) Classification of Cannabis Cultivars Marketed in Canada for Medical Purposes by Quantification of Cannabinoids and Terpenes Using HPLC-DAD and GC-MS. Journal of Analytical \& Bioanalytical Techniques, 8, 349. https://doi.org/10.4172/2155-9872.1000349

[11] Health Canada (2013) Information for Health Care Professionals: Cannabis (Marihuana, Marijuana) and the Cannabinoids.

[12] Potter, D.J. (2014) A Review of the Cultivation and Processing of Cannabis (Cannabis sativa L.) for Production of Prescription Medicines in the UK. Drug Testing and 
Analysis, 6, 31-38. https://doi.org/10.1002/dta.1531

[13] Fetterman, P.S., Keith, E.S., Waller, C.W., Guerrero, O., Doorenbos, N.J. and Quimby, M.W. (1971) Mississippi-Grown Cannabis sativa L.: Preliminary Observation on Chemical Definition of Phenotype and Variations in Tetrahydrocannabinol Content versus Age, Sex, and Plant Part. Journal of Pharmaceutical Sciences, 60, 1246-1249. https://doi.org/10.1002/jps.2600600832

[14] De Meijer, E.P.M. (2014) The Chemical Phenotypes (Chemotypes) of Cannabis. In: Pertwee, R., Ed., Handbook of Cannabis, Oxford University Press, Oxford, 89-110. https://doi.org/10.1093/acprof:oso/9780199662685.003.0005

[15] Pacifico, D., Miselli, F., Carboni, A., Moschella, A. and Mandolino, G. (2008) Time Course of Cannabinoid Accumulation and Chemotype Development during the Growth of Cannabis sativa L. Euphytica, 160, 231-240. https://doi.org/10.1007/s10681-007-9543-y

[16] De Backer, B., Maebe, K., Verstraete, A.G. and Charlier, C. (2012) Evolution of the Content of THC and Other Major Cannabinoids in Drug Type Cannabis Cuttings and Seedlings during Growth of Plants. Journal of Forensic Sciences, 57, 918-922. https://doi.org/10.1111/j.1556-4029.2012.02068.x

[17] Aizpurua-Olaizola, O.S. (2016) Evolution of the Cannabinoid and Terpene Content during the Growth of Cannabis sativa Plants from Different Chemotypes. Journal of Natural Products, 79, 324-331. https://doi.org/10.1021/acs.jnatprod.5b00949

[18] United Nations Office on Drugs and Crime (2009) Recommended Methods for the Identification and Analysis of Cannabis and Cannabis Products. United Nations, New York.

[19] Hillig, K. (2002) Letter to the Editor. Journal of Industrial Hemp, 7, 5-6. https://doi.org/10.1300/J237v07n01_02

[20] Clarke, R. and Merlin, M. (2016) Cannabis: Evolution and Ethnobotany. University of California Press, Oakland, CA.

[21] Office of Medicinal Cannabis (2003) Guidelines for Cultivating Cannabis for Medicinal Purposes.

[22] Sabeh, N. (2017) Maximizing Profitability: By Managing Plant-Environment Interactions. Marijuana Venture Magazine, 96-104.

[23] Magagnini, G., Grassi, G. and Kotiranta, S. (2018) The Effect of Light Spectrum on the Morphology and Cannabinoid Content of Cannabis sativa L. Medical Cannabis and Cannabinoids, 1, 19-27. https://doi.org/10.1159/000489030

[24] Malloy, K.D., Holman, M.A., Mitchell, D. and Detrich, H.W. (1997) Solar UVB-Induced DNA Damage and Photoenzymatic DNA Repair in Antarctic Zooplankton. Proceedings of the National Academy of Sciences of the United States of America, 94, 1258-1263. https://doi.org/10.1073/pnas.94.4.1258

[25] Ahmed, F.E. and Setlow, R.B. (1993) Ultraviolet Radiation-Induced DNA Damage and Its Photorepair in the Skin of the Platyfish Xiphophorus. Cancer Research, 53, 2249-2255.

[26] Pate, D.W. (1983) Possible Role of Ultraviolet Radiation in Evolution of Cannabis Chemotypes. Economic Botany, 37, 396-405. https://doi.org/10.1007/BF02904200

[27] Pate, D.W. (1994) Chemical Ecology of Cannabis. Journal of the International Hemp Association, 2, 32-37.

[28] Lydon, J., Teramura, A.H. and Coffman, C.B. (1987) UV-B Radiation Effects on Photosynthesis, Growth and Cannabinoid Production of Two Cannabis sativa Chemotypes. Photochemistry and Photobiology, 46, 201-206. 
https://doi.org/10.1111/j.1751-1097.1987.tb04757.x

[29] Vanhove, W., Van Damme, P. and Meert, N. (2011) Factors Determining Yield and Quality of Illicit Indoor Cannabis (Cannabis Spp.) Production. Forensic Science International, 212, 158-163. https://doi.org/10.1016/j.forsciint.2011.06.006

[30] Hawley, D., Graham, T., Stasiak, M. and Dixon, M. (2018) Improving Cannabis Bud Quality and Yield with Subcanopy Lighting. HortScience, 53, 1593-1599. https://doi.org/10.21273/HORTSCI13173-18

[31] Zelitch, I. (1975) Improving the Efficiency of Photosynthesis. Science, 188, 626-633. https://doi.org/10.1126/science.188.4188.626

[32] Chandra, S., Lata, H., Khan, I.A. and ElSohly, M.A. (2008) Photosynthetic Response of Cannabis sativa L. to Variations in Photosynthetic Photon Flux Densities, Temperature and $\mathrm{CO}_{2}$ Conditions. Physiology and Molecular Biology of Plants, 14, 299-306. https://doi.org/10.1007/s12298-008-0027-x

[33] Chandra, S., Lata, H., Khan, I.A. and ElSohly, M.A. (2011) Temperature Response of Photosynthesis in Different Drug and Fiber Varieties of Cannabis sativa L. Physiology and Molecular Biology of Plants, 17, 297.

https://doi.org/10.1007/s12298-011-0068-4

[34] Chandra, S., Lata, H., Mehmedic, Z., Khan, I.A. and ElSohly, M.A. (2015) Light Dependence of Photosynthesis and Water Vapor Exchange Characteristics in Different High $\Delta^{9}$-THC Yielding Varieties of Cannabis sativa L. Journal of Applied Research on Medicinal and Aromatic Plants, 2, 39-47. https://doi.org/10.1016/j.jarmap.2015.03.002

[35] Potter, D.J. (2009) The Propagation, Characterisation and Optimisation of Cannabis Sativa L as a Phytopharmaceutical. Ph.D. Thesis, King's College, London.

[36] Monteith, J.L. and Moss, C.J. (1977) Climate and the Efficiency of Crop Production in Britain. Philosophical Transactions of the Royal Society of London B: Biological Sciences, 281, 277-294. https://doi.org/10.1098/rstb.1977.0140

[37] Langhans, R.W. and Tibbitts, T.W. Growth Chamber Handbook-NCERA-101. North Central Regional Research Publication No. 340. https://www.controlledenvironments.org/growth-chamber-handbook/

[38] Potter, D.J. and Duncombe, P. (2012) The Effect of Electrical Lighting Power and Irradiance on Indoor-Grown Cannabis Potency and Yield. Journal of Forensic Sciences, 57, 618-622. https://doi.org/10.1111/j.1556-4029.2011.02024.x

[39] European Monitoring Centre for Drugs and Drug Addiction (2012) Cannabis Production and Markets in Europe.

[40] Clarke, R.C. (1981) Marijuana Botany. Ronin Publishing, San Francisco, CA.

[41] Nobel, P.S. (2005) Physicochemical and Environmental Plant Physiology. Academic Press, Amsterdam.

[42] Fischedick, J.T., Hazekamp, A., Erkelens, T., Choi, Y.H. and Verpoorte, R. (2010) Metabolic Fingerprinting of Cannabis sativa L., Cannabinoids and Terpenoids for Chemotaxonomic and Drug Standardization Purposes. Phytochemistry, 71, 20582073. https://doi.org/10.1016/j.phytochem.2010.10.001

[43] Sikora, V., Berenji, J. and Latković, D. (2011) Influence of Agroclimatic Conditions on Content of Main Cannabinoids in Industrial Hemp (Cannabis sativa L.). Genetika, 43, 449-456. https://doi.org/10.2298/GENSR1103449S

[44] Bazzaz, F.A., Dusek, D., Seigler, D.S. and Haney, A.W. (1975) Photosynthesis and Cannabinoid Content of Temperate and Tropical Populations of Cannabis sativa. Biochemical Systematics and Ecology, 3, 15-18. 
https://doi.org/10.1016/0305-1978(75)90036-8

[45] Chandra, S., Lata, H., Khan, I.A. and ElSohly, M.A. (2013) The Role of Biotechnology in Cannabissativa Propagation for the Production of Phytocannabinoids. In: Chandra, S., Lata, H. and Varma, A., Eds., Biotechnology for Medicinal Plants, Springer, Berlin, Heidelberg, 123-148. https://doi.org/10.1007/978-3-642-29974-2_5

[46] Monteith, J. and Unsworth, M. (2013) Principles of Environmental Physics: Plants, Animals, and the Atmosphere. Academic Press, Cambridge, MA.

[47] Caplan, D.M. (2018) Propagation and Root Zone Management for Controlled Environment Cannabis Production. Ph.D. Thesis, University of Guelph, Guelph and Toronto, Ontario.

[48] Coffman, C.B. and Gentner, W.A. (1975) Cannabinoid Profile and Elemental Uptake of Cannabis sativa L. as Influenced by Soil Characteristics. Agronomy Journal, 67, 491-497. https://doi.org/10.2134/agronj1975.00021962006700040010x

[49] Caplan, D., Dixon, M. and Zheng, Y. (2017) Optimal Rate of Organic Fertilizer during the Vegetative-Stage for Cannabis Grown in Two Coir-Based Substrates. HortScience, 52, 1307-1312. https://doi.org/10.21273/HORTSCI11903-17

[50] Chen, J., Beeson Jr., R.C., Yeager, T.H., Stamps, R.H. and Felter, L.A. (2003) Evaluation of Captured Rainwater and Irrigation Runoff for Greenhouse Foliage and Bedding Plant Production. HortScience, 38, 228-233.

https://doi.org/10.21273/HORTSCI.38.2.228

[51] Swistock, B. (2016) Interpreting Irrigation Water Tests. Penn State Extension. https://extension.psu.edu/interpreting-irrigation-water-tests

[52] Bruci, Z., Papoutsis, I., Athanaselis, S., Nikolaou, P., Pazari, E., Spiliopoulou, C. and Vyshka, G. (2012) First Systematic Evaluation of the Potency of Cannabis sativa Plants Grown in Albania. Forensic Science International, 222, 40-46. https://doi.org/10.1016/j.forsciint.2012.04.032

[53] Vanhove, W. (2014) The Agronomy and Economy of Illicit Indoor Cannabis Cultivation. Ghent University, Ghent, Belgium.

[54] Coffman, C.B. and Gentner, W.A. (1977) Responses of Greenhouse-Grown Cannabis sativa L. to Nitrogen, Phosphorus, and Potassium. Agronomy Journal, 69, 832 836. https://doi.org/10.2134/agronj1977.00021962006900050026x

[55] Bócsa, I., Máthé, P. and Hangyel, L. (1997) Effect of Nitrogen on Tetrahydrocannabinol (THC) Content in Hemp (Cannabis sativa L.) Leaves at Different Positions. Journal of the International Hemp Association, 4, 78-79.

[56] Knight, G., Hansen, S., Connor, M., Poulsen, H., McGovern, C. and Stacey, J. (2010) The Results of an Experimental Indoor Hydroponic Cannabis Growing Study, Using the 'Screen of Green' (ScrOG) Method-Yield, Tetrahydrocannabinol (THC) and DNA Analysis. Forensic Science International, 202, 36-44.

https://doi.org/10.1016/j.forsciint.2010.04.022

[57] Hazekamp, A., Sijrier, P. and Verpoorte, R. (2006) An Evaluation of the Quality of Medicinal Grade Cannabis in the Netherlands. Cannabinoids, 1, 1-9.

[58] Turner, J.C. and Mahlberg, P.G. (1984) Effects of Sample Treatment on Chromatographic Analysis of Cannabinoids in Cannabis sativa L. (Cannabaceae). Journal of Chromatography A, 283, 165-171. https://doi.org/10.1016/S0021-9673(00)96251-4

[59] Turner, C.E., Hadley, K.W., Fetterman, P.S., Doorenbos, N.J., Quimby, M.W. and Waller, C. (1973) Constituents of Cannabis sativa L. IV: Stability of Cannabinoids in Stored Plant Material. Journal of Pharmaceutical Sciences, 62, 1601-1605. 
https://doi.org/10.1002/jps.2600621005

[60] Taschwer, M. and Schmid, M.G. (2015) Determination of the Relative Percentage Distribution of THCA and $\Delta^{9}$-THC in Herbal Cannabis Seized in Austria-Impact of Different Storage Temperatures on Stability. Forensic Science International, 254, 167-171. https://doi.org/10.1016/j.forsciint.2015.07.019

[61] Abascal, K., Ganora, L. and Yarnell, E. (2005) The Effect of Freeze Drying and Its Implications for Botanical Medicine: A Review. Phytotherapy Research, 19, 655-660. https://doi.org/10.1002/ptr.1651 